\title{
Perancangan Keamanan Internet Jaringan Hotspot Mikrotik pada Winbox dan Wireshark
}

\author{
Rahmat Novrianda Dasmen ${ }^{1}$, Abdur Rohman Syarif ${ }^{2}$, Heru Saputra ${ }^{3}$, Rahmat \\ Amrullah $^{4}$ \\ ${ }_{1,2,3,4}$ Univesitas Bina Darma \\ email: rahmat.novrianda.d@gmail.com
}

\begin{abstract}
Mikrotik, a technology that provides Internet services by turning computers into network routers. The computer network of SMA Negeri 16 Palembang uses a traditional cable network with star type. In this research, the process of designing a network using Mikrotik and managing and distributing bandwidth as needed at SMA Negeri 16 Palembang is carried out using the Network Development Life Cycle (NDLC) model. The result of this research is that Mikrotik can manage all computer networks. In the distribution of bandwidth regularly on the proxy can provide efficiency over the use of the internet. Mikrotik can maximize network usage if the overall bandwidth has been set.
\end{abstract}

Keywords: Mikrotik, Computer Network, Router and Type Network

Abstrak: Mikrotik, teknologi yang menyediakan layanan Internet dengan mengubah komputer menjadi router jaringan. Jaringan komputer SMA Negeri 16 Palembang menggunakan jaringan kabel secara tradisional dengan type star. Pada penelitian ini dilakukan proses perancangan jaringan dengan menggunakan Mikrotik serta mengatur dan mendistribusikan bandwidth sesuai kebutuhan pada SMA Negeri 16 Palembang menggunakan model Network Development Life Cycle (NDLC). Hasil dari penelitian ini adalah mikrotik dapat mengelola semua jaringan komputer. Dalam Pembagian bandwith secara teratur pada mikrotik dapat memberikan efisiensi atas penggunaan internet. Mikrotik dapat memaksimalkan pengunaan jaringan jika bandwidth telah diatur secara keseluruhan.

Kata kunci: Mikrotik, Jaringan Komputer, Router dan Tipe Jaringan

\section{Pendahuluan}

Pada mikrotik terdapat salah satu paket bandwidth management dan user management, sebuah perangkat yang dipakai untuk mempermudah dalam setting bandwith dan management user ialah mikrotik. Dalam hal ini penulis melakukan sebuah upaya, bagaimana caranya agar semua pemakai internet merasa nyaman, tidak terganggu sinyal dan dapat melakukan akses ke dalam internet yang sudah dipermudah dengan adanya mikrotik. Mikrotik mempermudah administrasi melakukan settingan bandwidth. Mudah-mudahan dalam pengaturan setingg bandwidth dan pembagiannya, bisa memenuhi semua kebutuhan bandwidth (Sukendar, 2017). Mikrotik juga merupakan perangkat lunak independent Linux spesifik buat personal komputer yg digunakan menjadi Router, yg bisa digunakan menjadi gateway network yg ahli, meliputi beberapa fitur buat network \& wireless, dan nir butuh spesifikasi personal komputer yg tinggi (Herlambang, 2008).

Pada SMA Negeri 16 Palembang fasilitas internet yang terdapat masih bersifat terbuka dan bisa dibilang kurang mengoptimalkan dengan benar padahal fasilitas yang ada di SMA Negeri 16. terbilang lengkap. Fasilitas di SMA 16 terdapat laboratorium Perpustakaan, laboratoium Komputer dan laboratorium IPA tetapi internet yang ada sering terputus koneksi dan internet yang lambat (Bhayangkara \& Riadi, 2014). Dalam permasalahan tersebut harus ada pengelolaan manajemen dan juga dalam melakukan diimplementasi ke firewall 
untuk penelitian ini, yg akan dipakai buat memblok akses beberapa media sosial. Pada penelitian sebelumnya, Firewall Filter Rules bisa dipakai buat menaikkan Keamanan Jaringan berbasis Mikrotik bandwidth yg benar, sang admin jaringan pada sekolahan tersebut (Mardiyana, 2015).

Jaringan komputer merupakan Kebutuhan akan teknologi fakta pada era terbaru ketika ini sangat akbar dan bisa diaplikasikan pada aneka macam bidang, sebab banyaknya oknumoknum yang bergantung pada system komputer saat ini, Mengakibatkan system komputer berjalan setiap waktu di jaringan internet (Khairunnisa \& Sutarti, 2017).

Hal ini jadi inti permasalahan disaat jaringan internet pada SMA lain bagus tanpa adanya masalah jaringan, sehingga merasa nyaman dan dapat mengakses tanpa adanya masalah karena pengelolaan bandwidth yang benar. Oleh karena itu, penulis perlu menyiapkan jaringan hotspot untuk memungkinkan akses internet dari mana saja disekolah agar dapat mengoptimalkan bandwidth yang tersedia (Saputra et al., 2018). Penulis melakukan perancang jaringan hotspot server berbasis mikrotik winbox pada SMA Negeri 16 Palembang. Jaringan personal komputer adalah gugusan menurut beberapa personal komputer \& teknologi komunikasi, deretan menurut poly personal komputer yang terpisah satu sama lain tetapi saling berhubungan dalam pelaksanaan tugasnya (Tanenbaum \& Wetherall, 2011). Merupakan perkembangan pesat jaringan komputer khususnya melalui internet saat ini sudah menaruh efek \& manfaat yg signifikan bagi pengguna individu ataupun kelompok (Warman \& Andrian, 2017). Jaringan internet area pada mana pengguna bisa mengakses jaringan hospot selama handphone atau laptop tadi masih terkoneksi ke jaringan hotspot (Kuswanto, 2017).
WiFi "nirkabel fidelitas" mereka bisa mengakses Internet tanpa media kabel Sebuah kata yg dipakai buat menggambarkan. Mengakses hotspot yaitu lokasi loka dimana bisa mengakses internet melalui jaringan area lokal nirkabel, memakai router yg terhubung ke penyedia layanan Internet (ISP) anda (Ghozali, 2021). Kebanyakan orang menyebutnya menggunakan hotspot atau hotspot wifi. Jaringan hotspot tanpa kita sadari tak jarang kita jumpai pada sekolahan, kampus \& terkadang pada jalan pun ada. berdasarkan PC atau contohnya Handphone pada jangkauan radius beberapa ratus meteran dan juga signal tergantungan berdasarkan frekuensi (Diplan \& Ratih Alkindi, 2020). Hotspot gateway adalah satu fitur yang terdapat ada pada Mikrotik RouterOs (Muin \& Sugiantoro, 2017). Hotspot gateway dipakai buat mengkonfigurasi jaringan wireless dan hanya sanggup bisa digunakan memakai username \& password tertentu (Aprilianto \& Arifin, 2018).

Perangkat router mikrotik dalam manajemen jaringan nir tau bahwa terdapat bahaya yg akan ada bagi pemakai hotspot, ditimbulkan sang konfigurasi baku dalam layanan hotspot \& ARP. Ini sebagai sebuah perseteruan bagi pihak penyedia layanan hospot lantaran pada pengaturan jaringan hospot menggunakan router mikrotik (Hasibuan, 2021). Tujuan menurut penelitian membandingkan performa penyedai layanan jaringan internet berbasis wireless dalam layanan ISP (Utami, 2020).

\section{Metode Penelitian}

Untuk metode penelitian ini, kami memakai pendekatan menggunakan Network Development Life Cycle (NDLC) bisa digambarkan pada pada diagram dalam gambar dibawah ini (Dasmen, 2018). 


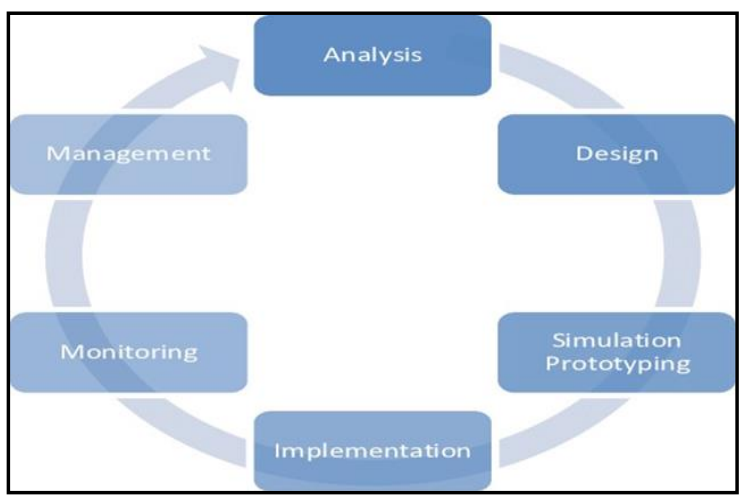

Gambar 1. Pendekatan NDLC

\section{Analisis (Analysis)}

Tahap pertama yg dilakukan menganalisis seluruh pertarungan yg terdapat, menganalisis user data, menganalisis kebutuhan hardware juga bandwith \& mengatur settingan mikrotik.

\section{Perancangan (Design)}

Tahap ke 2 yaitu design, Kumpulan suatu pandangan baru yg akan pada untuk pola \& bentuk yg kita inginkan dalam penerapannya. Desain tadi bisa mengakses kabel yg menaruh mengenai proyek yg akan dibuat.

\section{Simulasi (Simulation)}

Simulation, dilakukan penerapan sistem jaringan LAN pada Lab Komputer SMA Negeri 16 Palembang.

\section{Implementasi (Implementation)}

Pada tahap implementasi ini diterapkan vlan setting, keamanan hotspot, ARP dan perlengkapan manajemen internet yang sudah tersedia pada fitur mirkotik routerboard. Implementasi akan diawali dengan konfigurasi fitur-fitur tersebut (Kurniati \& Dasmen, 2019).

\section{Monitoring}

Monitoring dilakukan untuk memonitor dengan baik trafik yang berjalan pada internet, memonitor aktivitas pengguna, melihat koneksi yang aktif pada jaringan, dan melihat hasil pengukuran bandwidth di seluruh jaringan.

\section{Management}

Management melakukan sebuah tahapan dalam mengelola, agar sistem yang telah dirancang dari awal berjalan sesuai dengan apa yang ditelah dipikirkan. Tahapan yang akan dilakukan:

a) Membangun loka masuk (login) dalam hotspot supaya nir sembarang orang pengguna internet mampu masuk ke jaringan sekolah.

b) Melakukan backup data telebih dahulu supaya hal yg nir diinginkan mampu diantisipasi lewat backup data \& memberikan bandwidth sinkron kebutuhan setiap user.

\section{Hasil}

Penggunaan bandwidth belum optimal, SMA Negeri 16 masih memiliki kekurangan dalam pengaturan bandwidth dan distribusi bandwidth. Alat yang digunakan Router wifi, kabel LAN, dan mikrotik sebagai media penghubung.

TCP/IP merupakan komunikasi yang sudah standar yang digunakan dalam komunikasi ketika data dilewatkan dari komputer ke komputer yang lain. Sebelum metode diterapkan dan sesudah metode diterapkan jumlah paket ARP mengalami pengurangan. Laptop spoofing mengirim serangan jumlah paket ARP pada laptop client.

Mikrotik merupakan perangkat manajemen jaringan yang diakses dan bisa dikendalikan dari jarak jauh dengan berbagai cara, salah satunya juga bisa memakai winbox. Banyak orang menggunakan winbox untuk mengkonfigurasi router mikrotik pada manajemen jaringan, winbox dapat bergerak disistem operasi windows.

Perangkat router mikrotik pada manajemen jaringan tidak tau bahwa ada bahaya yang akan muncul bagi pemakai hotspot, disebabkan oleh konfigurasi standar pada layanan 
hotspot dan ARP. Ini menjadi sebuah permasalahan bagi pihak penyedia layanan hospot karena dalam pengaturan jaringan hospot memakai router mikrotik.

Pada winbox RouterBoard mikrotik muncul secara otomatis, jika topologi sudah benar. Berikut ini merupakan tampilan winbox. Setelah itu kita masukkan akses router mikrotik di Mac Address.

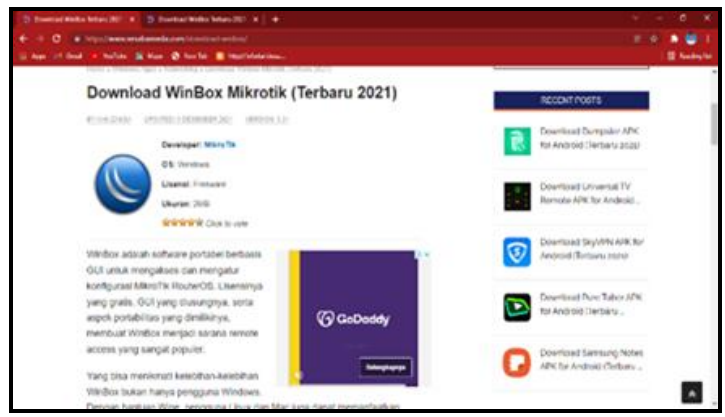

Gambar 2. Download Winbox

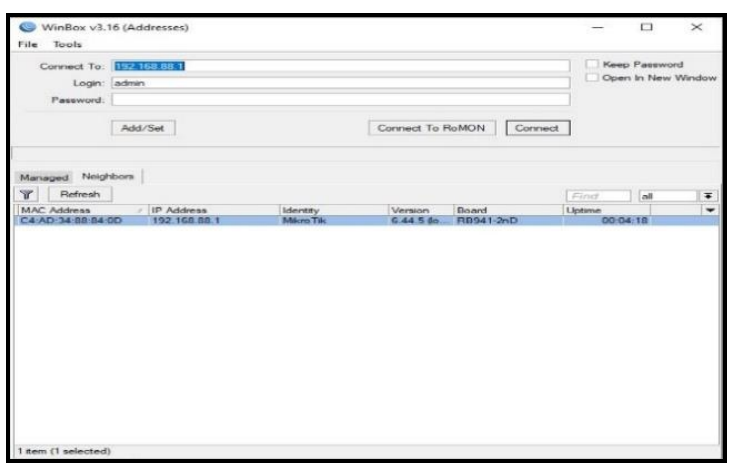

Gambar 3. Halaman Utama Winbox

Tampilan menu winbox saat melakukan akses ke Mac Address. Pada tampilan ini buka tampilan menu IP $>$ Hotspot.

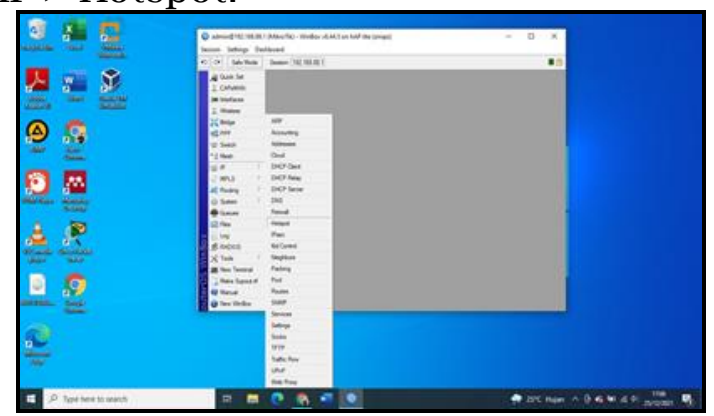

Gambar 4. Mac Address

Setelah itu klik tombol hotspot setup akan muncul wizard hotspot yang akan mengarahkkan untuk setting dengan tampilan di gambar bawah ini.

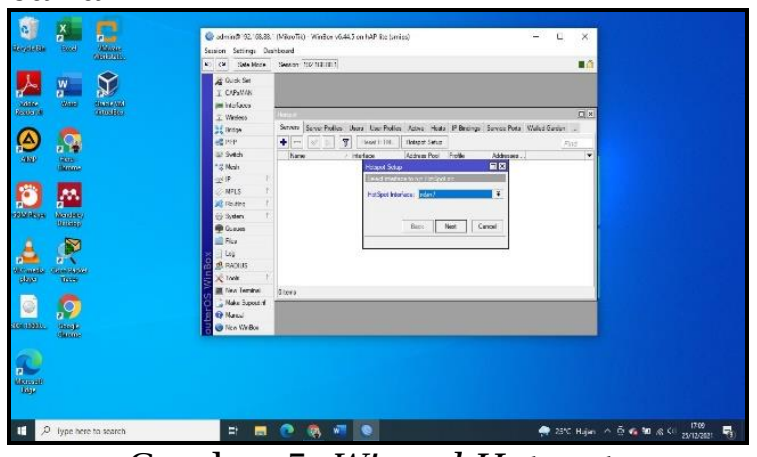

Gambar 5. Wizard Hotspot

Disini menentuhkan interface mana, hotspot akan diaktifkan. Pertama ketik pada wlan1, sudah di setting sebagai access point.

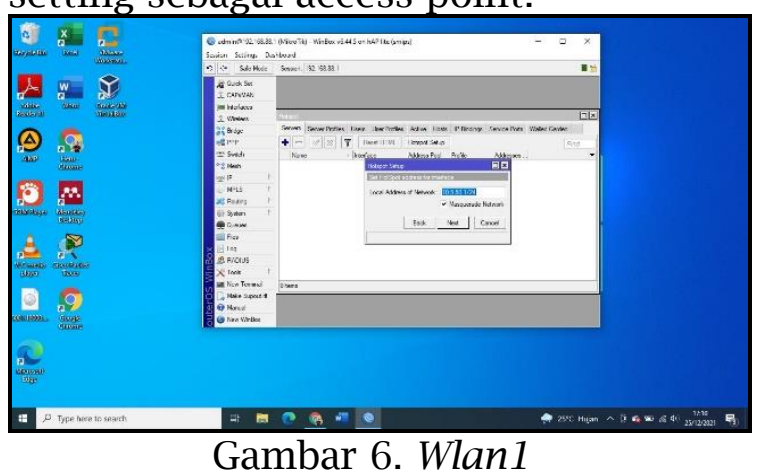

Setelah setting wlan1 sudah terdapat ip.

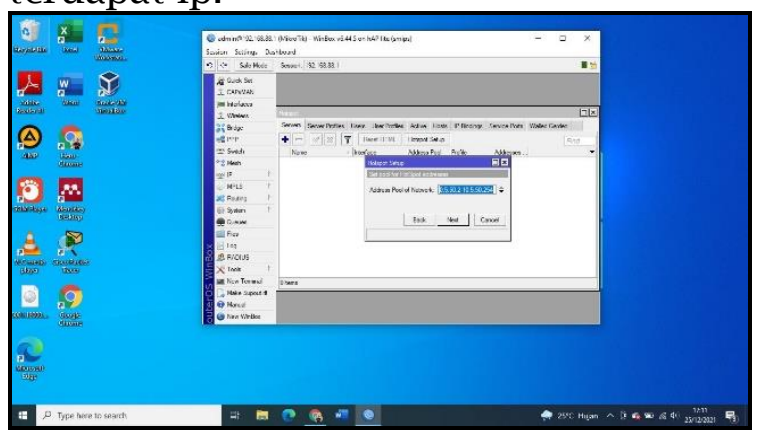

Gambar 7. IP Wlan1

Tentukan ke user server yg akan pada berikan ke user ip address. Namun secara langsung default router muncul range ip sinkron menggunakan subnet IP yg ada di interface. 


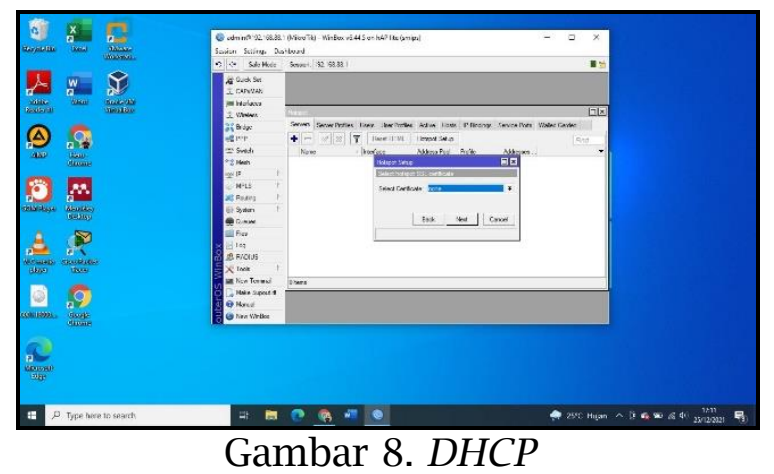

IP SMTP Server buat server hotspot sanggup dipengaruhi sebagai akibatnya setiap request SMTP client diredirect ke SMTP yg kita tentuhkan.IP 0.0.0.0 abaikan default.

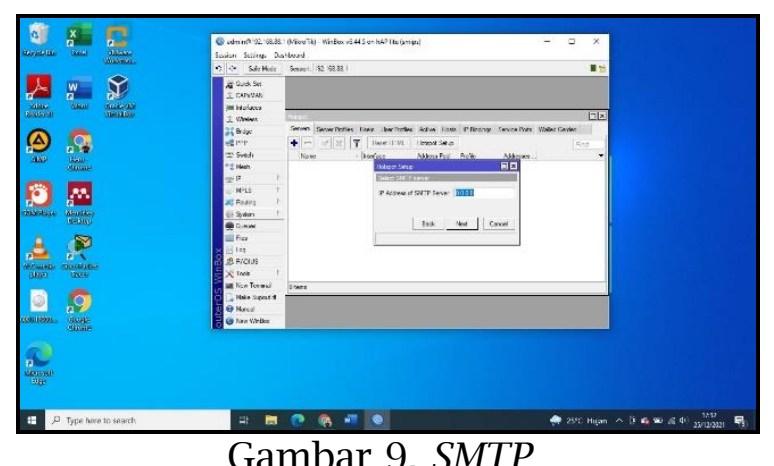

Langkah ini alamat IP DNS server, yang bisa isi dengan DNS yang diberikan oleh ISP.

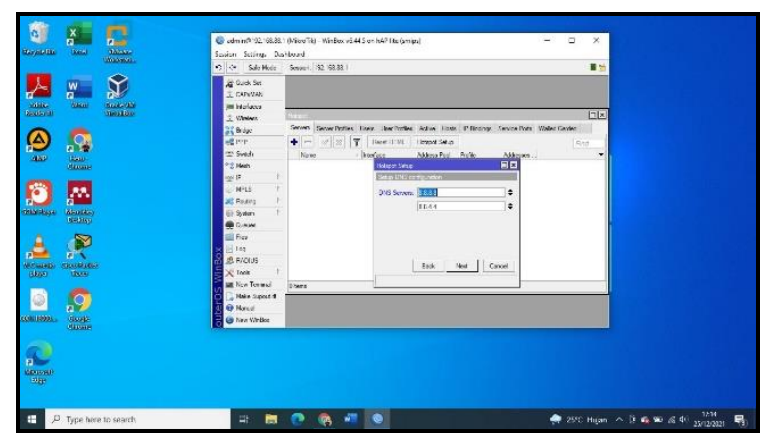

Gambar 10. DNS Server

Selanjutnya memasukan DNS buat local hostpot server. Setelah pada isi setiap dns server yang belum untuk mengakses ke nternet maka akan ke laman login sendiri.

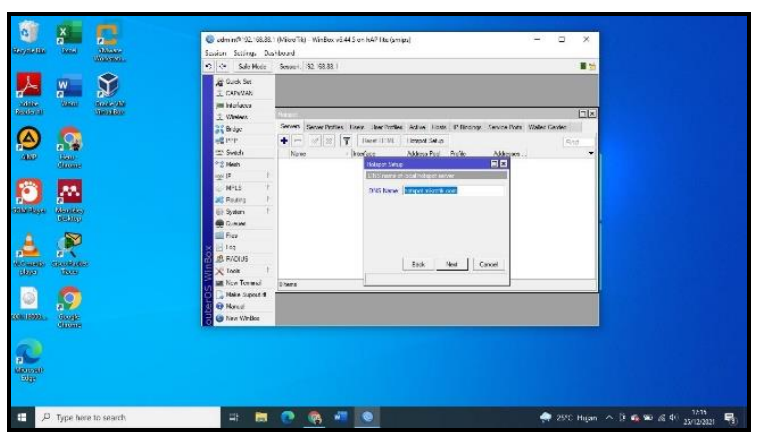

Gambar 11. Hotspot Server

Selanjutnya buat username dan password agar bisa login ke jaringan hotspot. Username ini bisa kita gunakan untuk akses jaringan hotspot.

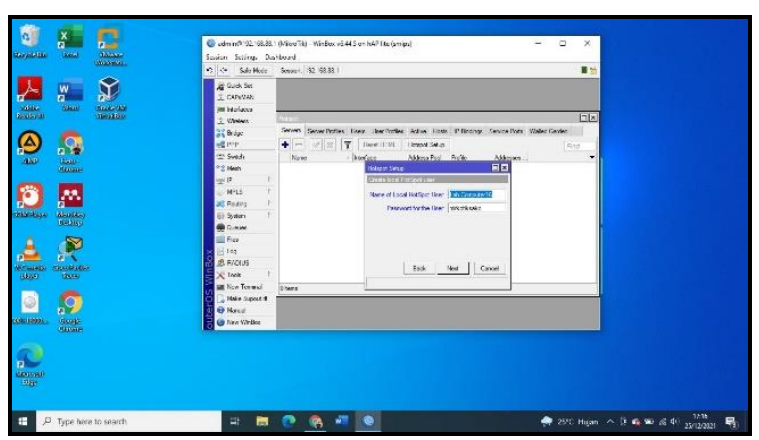

Gambar 12. Setup Login Hotspot

Setelah itu akan muncul pesan yang "Setup has completed successful" ini tanda sudah hotspot sudah selesai.

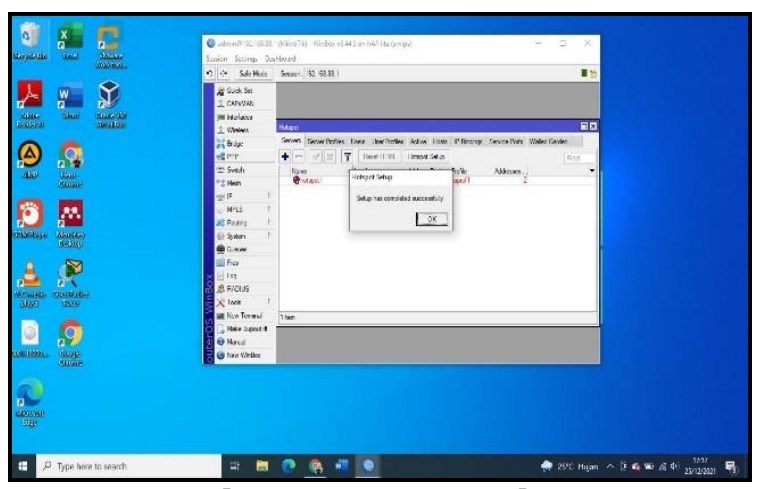

Gambar 13. Setup Selesai

Melakukan internet pada jaringan laptop ke wifi hotspot yang sudah dibuat. Setelah mengakses browser \& akses web buat menggunkan http, lantaran hotspot mirkotik belum support buat redirect web yg memakai http.Ini halaman login pada hospot. 


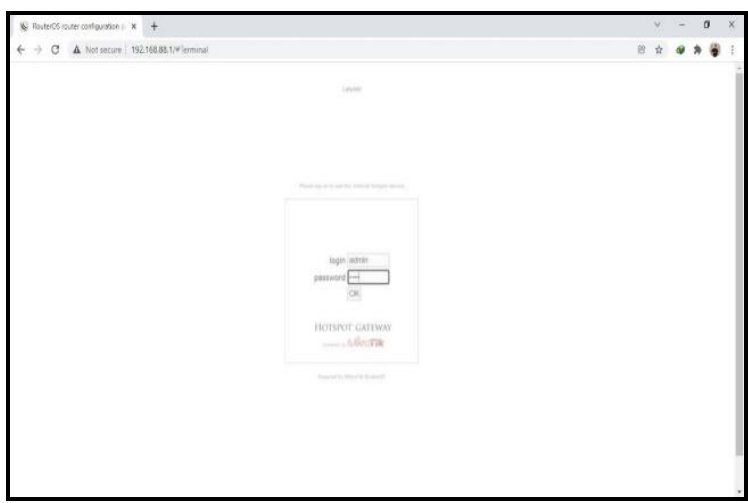

Gambar 14. Login Hotspot

Interfaces dapat melihat perangkat yang sedang terhubung pada port router mirkotik. klik wlan untuk mengaktikan hotspot yang akan dibuat.

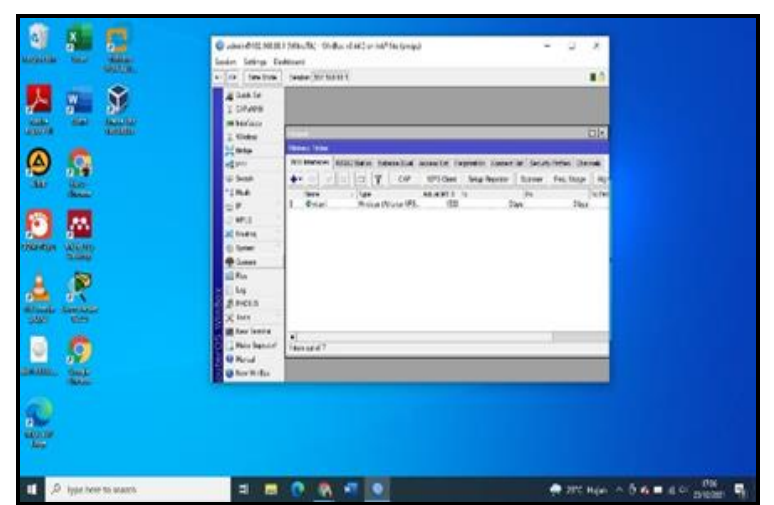

Gambar 15. Interface

Centang enable pada interface list setelahnya klik wan lalu menggatur wireless, inilah cara mengaktifkannya.

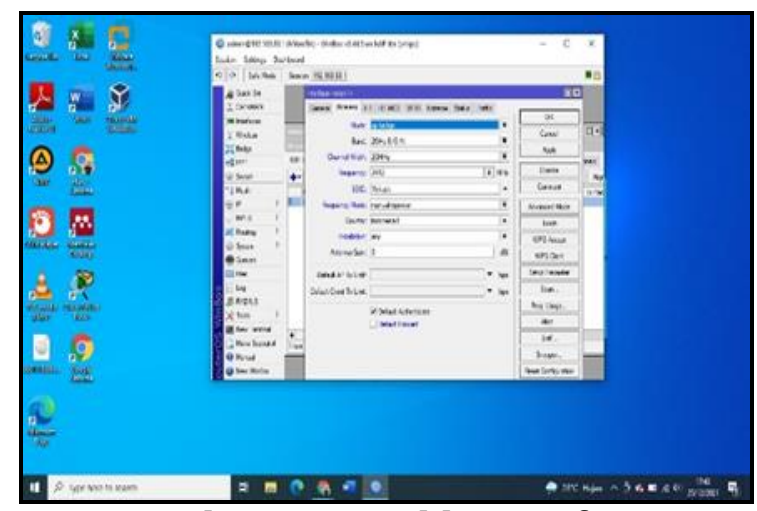

Gambar 16. Enable Interface

Pengujian sistem keamanan jaringan hotspot. Wireshark memantau trafik ARP pada jaringan sistem keamanan yang telah dikonfigurasi. Untuk menguji kesuksesan dilakukan perbandingan jumlah ARP yang diterima, sebelum dan sesudah pengujian.

1. Monitoring paket ARP.

Buka aplikasi wireshark kemudian pilih klik start.

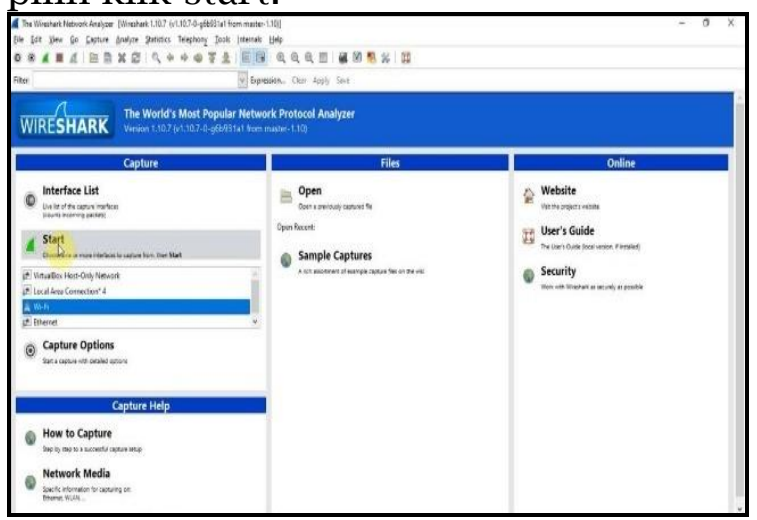

Gambar 17. Halaman Utama wireShark

Selanjutnya setelah klik start jaringan wifi akan muncul seluruh tampilan protocol aplikasi wireshark. Jika ingin melihat semua protocol ARP, anda dapat ketik di kolom pencarian dengan cara ketik arp lalu enter.

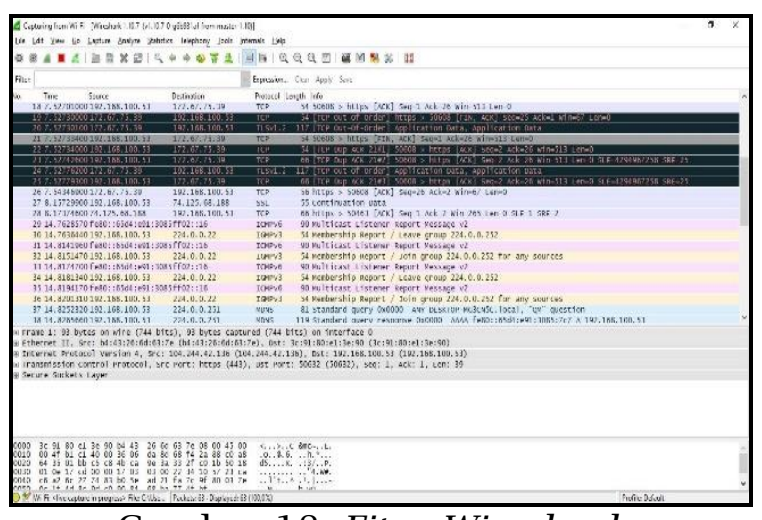

Gambar 18. Fitur Wireshark

Setelah pencarian ARP, akan muncul protokol ARP secara spesifik.dan gambar bawah ini merupakan proses komunikasi yang stabil antara client router sebelum penyerangan ARP Spoofing. 


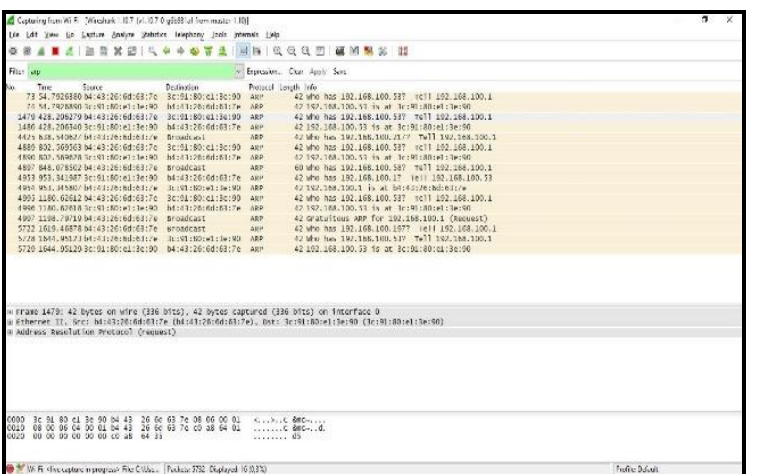

Gambar 19. ARP

2. Pengujian koneksi client

Pengujian ini dilakukan pada laptop client yang terkoneksi wifi, lalu laptop spoofing mencoba penyerangan pemalsuan mac address pada laptop.

Sebelum melakukan penerapan jumlah ARP diterima sebanyak 1800 lebih dan terpantau menyambung pada internet crash.

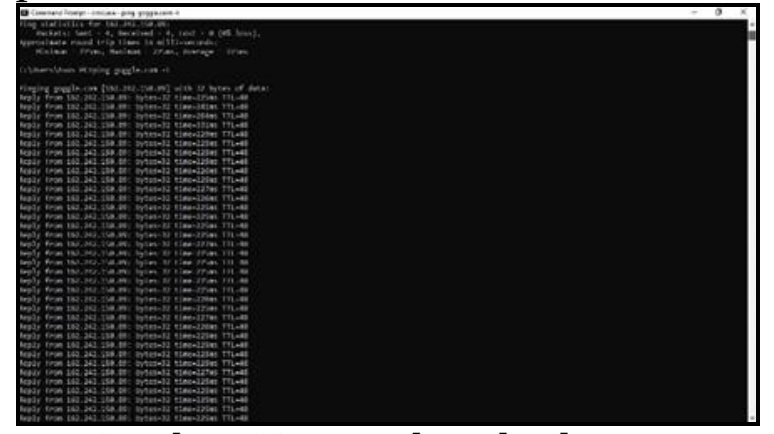

Gambar 20. ping koneksi laptop pertama

Selanjutnya melakukan penerapan metode jumlah ARP dari serangan sebanyak 150 koneksi dan setelah melakukan ternyata koneksi masih stabil.

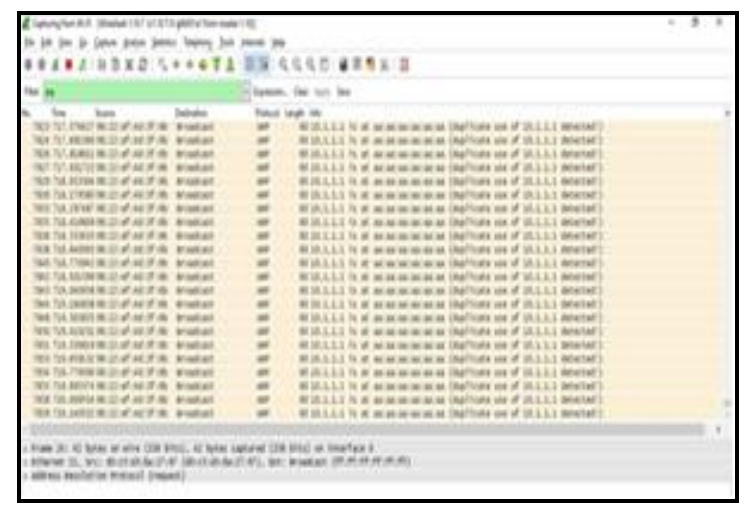

\section{Gambar 21. Protocol ARP}

Percobaan laptop kedua sebelum penerapan metode dapat dilihat jumlah ARP yang diterima sebanyak 10000 lebih paket ARP dan terlihat koneksi ke internet terhambat.

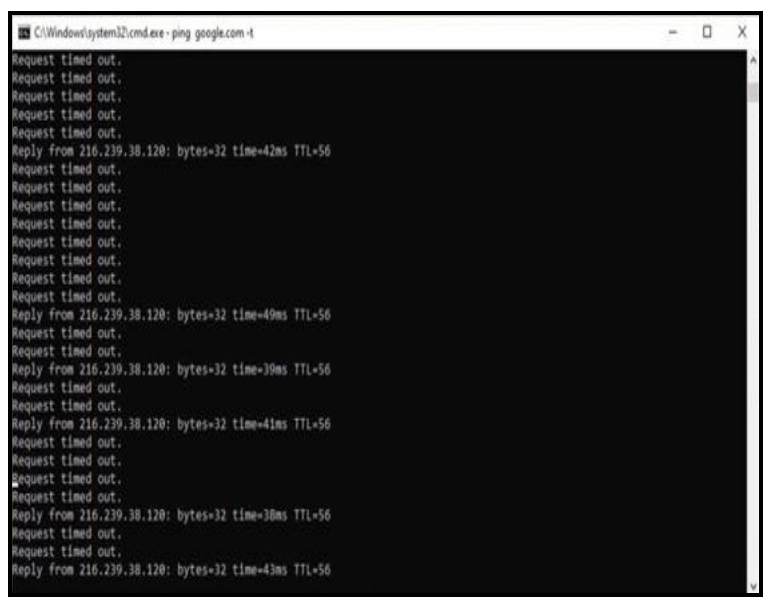

Gambar 22. Pengujian koneksi laptop kedua

\section{Simpulan}

Dengan adanya mikrotik seluruh jaringan yang ada dapat dioptimalkan dengan baik, winbox mempermudah pengaturan mikrotik dan konfigurasi mikrotik menggunakan mac address. Pembagian bandwidth secara keseluruhan dapat membantu permasalahan jaringan yang ada pada sekolahan, mikrotik dapat mengetahui jika ada kerusakan pada pc.

Sistem keamanan jaringan pada sekolahan diuji dengan ARP ysng menggunakan wireshark, dari hasil pengujian yang dilakukan berhasil dan sukses pada jumlah ARP terpantau menurun setelah dilakukan pengujian. Mengatur static di layanan DHCP agar ARP table tidak melakukan update saat sedang koneksi ke internet. Oleh karena itu komunikasi antar client akan dibatasi oleh mikrotik, agar Spoofer tidak bisa lagi melakukan serangan sehingga koneksi pengguna pada jaringan hotspot bisa terkendali.

\section{Referensi}

Aprilianto, T., \& Arifin, S. (2018). 
Perancangan dan Implementasi Hotspot Cerdas Berbasis Mikrotik OS dan Web Server Mini PC Raspberry Pi. Jurnal Sistem Dan Teknologi Informasi (POSITIF), 4(2), 223-226.

Bhayangkara, F. J., \& Riadi, I. (2014). Implementasi Proxy Server dan Load Balancing Menggunakan Metode Per Connection Classifier (PCC) Berbasis Mikrotik (Studi kasus: Shmily. net). In Diss. Universitas Ahmad Dahlan. https://doi.org/10.12928/jstie.v2 i2. 2729

Dasmen, R. N. (2018). Implementasi Authentication Captive Portal pada Wireless Local Area Network PT. Rikku Mitra Sriwijaya. Register: Jurnal Ilmiah Teknologi Sistem Informasi, 4(2), 67-80.

Diplan, \& Ratih Alkindi, Z. (2020). Analisis Penerapan Media Pembelajaran Berbasis E-Learning (Google Classroom). Neraca: Jurnal Pendidikan Ekonomi, 5(2). https://doi.org/10.33084/neraca. v5i2.1422

Ghozali, M. I. (2021). Otomatisasi Pemusatan Jaringan IPv4 dan IPv6 menggunakan Riverbed Modeler. Jurnal INSTEK (Informatika Sains Dan Teknologi), 5(1). https://doi.org/10.24252/instek. v5i1.13687

Hasibuan, F. A. (2021). Jaringan Komputer Berbasis Radius Server untuk Meningkatkan Pemanfaatan Internet di Madrasah Aliyah Al-Azhaar Ummu Suwanah. Jurnal Teknik Informatika, $\quad 7(1), \quad 30-39$. https://doi.org/10.51998/jti.v7i1 .349

Herlambang, M. et all. (2008). Panduan Lengkap Menguasai Router Masa Depan Mikrotik Router.

Khairunnisa, \& Sutarti. (2017). Perancangan Dan Analisis Keamanan Jaringan Nirkabel Dari
Serangan Ddos ( Distributed Denial of Service ) Berbasis Honeypot. Jurnal PROSISKO, 4(2).

Kurniati, \& Dasmen, R. N. (2019). The Simulation of Access Control List (ACLs) Network Security for Frame Relay Network at PT. KAI Palembang. Lontar Komputer: Jurnal Ilmiah Teknologi Informasi, 10(1), 49-61.

Kuswanto, H. (2017). Sistem Autentikasi Hotspot Menggunakan Radius Server Mikrotik Router. Informatics for Educators and Professionals, 2(1).

Mardiyana, I. G. K. O. (2015). Keamanan Jaringan Dengan Firewall Filter Berbasis Mikrotik Pada Laboratorium Komputer STIKOM Bali. Stmik Stikom, 86.

Muin, M. A., \& Sugiantoro, B. (2017). Implementasi Firewall dengan menggunakan MIKROTIK ROUTEROS $^{\mathrm{TM}}$ (Studi Kasus : STMIK Bina Patria). JURNAL TRANSFORMASI, 13(1).

Saputra, A., Raehan, S., \& Asmar, K. (2018). Analisis Rancangan Jaringan Komputer dalam Mendukung E-Government. In $C V$. Kitami.

Sukendar, T. (2017). Keseimbangan Bandwidth Dengan Menggunakan Dua ISP Melalui Metode Nth Load Balancing Berbasiskan Mikrotik. Jurnal Teknik Komputer Amik Bsi, III(1).

Tanenbaum, A. S., \& Wetherall, D. J. (2011). Computer Networks, 5th Edition. In World Wide Web Internet And Web Information Systems (Vol. 52, Issue 169).

Utami, P. R. (2020). Analisis Perbandingan Quality Of Service Jaringan Internet Berbasis Wireless Pada Layanan Internet Service Provider (ISP) Indihome Dan First Media. Jurnal Ilmiah Teknologi Dan Rekayasa, 25(2), 125-137.

https://doi.org/10.35760/tr.2020 .v25i2.2723 
Warman, I., \& Andrian, A. (2017). Analisis Kinerja Load Balancing Dua Line Kineksi DenganN Metode Nth (Studi Kasus:
Laboratorium Teknik Informatika Institut Teknologi Padang). Jurnal TEKNOIF, 5(1). 